\title{
Escitalopram Enhances the Association of Serotonin-1A Autoreceptors to Heteroreceptors in Anxiety Disorders
}

\author{
Andreas Hahn, ${ }^{1}$ Rupert Lanzenberger, ${ }^{1}$ Wolfgang Wadsak, ${ }^{2}$ Christoph Spindelegger, ${ }^{1}$ UIrike Moser, ${ }^{1}$ \\ Leonhard-Key Mien, ${ }^{2}$ Markus Mitterhauser, ${ }^{2}$ and Siegfried Kasper ${ }^{1}$ \\ Departments of ${ }^{1}$ Psychiatry and Psychotherapy and ${ }^{2}$ Nuclear Medicine, Medical University of Vienna, 1090 Vienna, Austria
}

Selective serotonin reuptake inhibitors (SSRIs) represent one of the most common treatment options in major depression and anxiety disorders. By blocking the serotonin transporter, SSRIs modulate serotonergic neurotransmission as well as the function of autoreceptors and heteroreceptors. However, treatment-induced changes on a network level primarily remain unknown. Thus, we evaluated the association between serotonin-1A $\left(5-\mathrm{HT}_{1 \mathrm{~A}}\right)$ autoreceptors and heteroreceptors before and after SSRIs. Twenty-one patients with anxiety disorders underwent positron emission tomography using $\left[\right.$ carbonyl $\left.{ }^{11} \mathrm{C}\right]$ WAY-100635 before and after 12 weeks of escitalopram treatment; 15 of them completed the study protocol. Additionally, 36 drug-naive healthy controls were measured once. The 5-HT ${ }_{1 \mathrm{~A}}$ receptor binding potential $\left(\mathrm{BP}_{\mathrm{ND}}\right)$ was quantified for the dorsal raphe nucleus (DRN) using a region-of-interest approach and for the entire brain by calculating parametric maps. Voxel-wise linear regression was applied between DRN autoreceptor and whole-brain heteroreceptor $5-\mathrm{HT}_{1 \mathrm{~A}} \mathrm{BP}_{\mathrm{ND}}$. Consistent with previous observations, healthy subjects showed widespread positive correlations of 5- $\mathrm{HT}_{1 \mathrm{~A}} \mathrm{BP}_{\mathrm{ND}}$ between autoreceptors and heteroreceptors. Comparing patients before versus after escitalopram treatment revealed enhanced associations of autoreceptor-to-heteroreceptor $5-\mathrm{HT}_{1 \mathrm{~A}} \mathrm{BP}_{\mathrm{ND}}$ within the amygdala and hippocampus $\left(R^{2}=0.21-0.28\right.$ vs $\left.0.49-0.81 ; p<0.05-0.001\right)$. In contrast, no significant SSRI-induced changes were found for correlations of heteroreceptor-to-heteroreceptor 5-HT ${ }_{1 \mathrm{~A}} \mathrm{BP}_{\mathrm{ND}}$ between several limbic regions. This interregional approach suggests a treatment-induced reinforcement of the association of 5-HT ${ }_{1 \mathrm{~A}}$ binding between autoreceptors and heteroreceptors specifically in areas involved in anxiety disorders. These findings provide complementary information about treatment effects on a network level and confirm the central role of the DRN as a prime regulatory area.

\section{Introduction}

Alterations in the serotonergic [5-hydroxytryptamine (5-HT)] neurotransmitter system have been associated with several psychiatric disorders (Fink and Gothert, 2007). In particular, the main inhibitory serotonin receptor $\left(5-\mathrm{HT}_{1 \mathrm{~A}}\right)$ seems to play a key role in major depression (Drevets et al., 2000; Hirvonen et al.,

\section{Received May 11, 2010; revised July 15, 2010; accepted Aug. 9, 2010.}

This research was partly supported by grants from the Austrian National Bank (R.L.) and the Austrian Science Fund and by an unrestricted investigator-initiated research grant from H. Lundbeck A/S (S.K.). We are grateful to the technical and medical team of the PET Centre, Medical University of Vienna, especially to K. Kletter and R. Dudczak. Furthermore, we thank P. Stein for recruiting and administrative support, M. Savli for support in the modeling procedures, and W. Huf for assistance in the statistical analysis.

This retrospective study was designed by the authors, who retain full academic control and are publishing the study independently from grant support. Without any relevance to this work, $S$. Kasper declares that he has received grant/research support from Eli Lilly, H. Lundbeck A/S, Bristol-Myers Squibb, Servier, Sepracor, GlaxoSmithKline, and Organon; has served as a consultant or on advisory boards for AstraZeneca, Austrian Sick Found, Bristol-Myers Squibb, GlaxoSmithKline, Eli Lily, H. Lundbeck A/S, Pfizer, Organon, Sepracor, Janssen, and Novartis; and has served on speakers' bureaus for AstraZeneca, Eli Lilly, H. Lundbeck A/S, Servier, Sepracor, and Janssen. R. Lanzenberger received travel grants and conference speaker honoraria from AstraZeneca and H. Lundbeck A/S. C. Spindelegger received a travel grant from H. Lundbeck A/S. U. Moser received travel grants from Bristol-Myers Squibb and AstraZeneca. A. Hahn received a travel grant from Pfizer. M. Mitterhauser and W. Wadsak received speaker honoraria from Bayer. L.-K. Mien reports no biomedical financial interests or potential conflicts of interest. Parts of this study were presented at the 22nd European College of Neuropsychopharmacology Congress in Istanbul, Turkey (2009), and the 26th Arbeitsgemeinschaft für Neuropsychopharmakologie and Pharmakopsychiatrie Symposium in Munich, Germany (2009).

Correspondence should be addressed to Prof. Siegfried Kasper, Department of Psychiatry and Psychotherapy, Medical University of Vienna, Waehringer Guertel 18-20, 1090 Vienna, Austria. E-mail: sci-biolpsy@ meduniwien.ac.at.

DOI:10.1523/JNEUROSCI.2409-10.2010

Copyright $\odot 2010$ the authors $\quad 0270-6474 / 10 / 3014482-08 \$ 15.00 / 0$
2008 ) and anxiety disorders (Gordon and Hen, 2004; Akimova et al., 2009). Animal studies further underline the involvement of the 5- $\mathrm{HT}_{1 \mathrm{~A}}$ receptor in anxiety-like behavior (Gross et al., 2002; Ögren et al., 2008).

Originating in the midbrain raphe nuclei, serotonergic neurons account for 5-HT release at terminal nerve ends within projection areas (Tork, 1990; Michelsen et al., 2008). In the human raphe nuclei, the vast majority $(80-100 \%)$ of $5-\mathrm{HT}_{1 \mathrm{~A}}$ receptors are located on cell bodies of serotonin neurons (Hornung, 2010) and have an autoinhibitory function (Fink and Gothert, 2007). Thus, activation of $5-\mathrm{HT}_{1 \mathrm{~A}}$ autoreceptors decreases the rate of serotonergic cell firing (Hajos et al., 2001; Evans et al., 2008), leading to a reduced 5-HT release (Parsons et al., 2001; Bundgaard et al., 2006). In contrast, outside the raphe region $5-\mathrm{HT}_{1 \mathrm{~A}}$ receptors are mainly situated on non-5-HT-containing neurons in projection areas [i.e., as heteroreceptors (Mengod et al., 2010)], inhibiting postsynaptic cell firing (Fink and Gothert, 2007).

Selective serotonin reuptake inhibitors (SSRIs) are one of the most common pharmacological treatments of anxiety disorders (Bandelow et al., 2002; Kasper et al., 2005), which decrease the clinical symptoms of anxiety (Sanchez et al., 2003) and depression (Blier et al., 1998) after sustained treatment. This has been attributed to a desensitization of $5-\mathrm{HT}_{1 \mathrm{~A}}$ autoreceptors in the raphe nuclei (Dawson et al., 2000), allowing the firing rate of serotonergic neurons to recover (Blier and De Montigny, 1983; El Mansari et al., 2005) and, together with 5-HTT blockade, increas- 
ing serotonergic neurotransmission (Blier and de Montigny, 1999). Furthermore, it seems that a multitude of 5-HT heteroreceptors are also altered by SSRI treatment (Le Poul et al., 2000; Meyer et al., 2001; Burghardt et al., 2007; Spindelegger et al., 2008), indicating adaptive mechanisms within the entire 5-HT system (El Mansari et al., 2005). However, it is not fully understood how treatment-induced changes in different parts of the 5-HT network are related to each other. In healthy subjects, strong correlations of $5-\mathrm{HT}_{1 \mathrm{~A}}$ receptors between the dorsal raphe nucleus (DRN) and projection areas were reported (Rabiner et al., 2002; Borg et al., 2006; Drevets et al., 2007). Although these interregional relationships might provide important complementary information on a network level, only few results describe such treatment-induced interactions (Bosker et al., 2001; Sprouse et al., 2001; El Mansari et al., 2005).

Therefore, this positron emission tomography (PET) study evaluates the association of $5-\mathrm{HT}_{1 \mathrm{~A}}$ receptor binding between the DRN (autoreceptors) and the entire brain (heteroreceptors) in healthy subjects and patients with anxiety disorders before and after continuous escitalopram treatment. Considering the widespread projections from the raphe nuclei (Tork, 1990) and the involvement of corresponding circuits in anxiety disorders (Lowry et al., 2005), our working hypothesis was to find SSRIinduced changes in the association between $5-\mathrm{HT}_{1 \mathrm{~A}}$ autoreceptors and heteroreceptors.

\section{Materials and Methods}

Participants. In total, PET data from 57 participants from previous work (Lanzenberger et al., 2007; Spindelegger et al., 2008; Stein et al., 2008; Fink et al., 2009; Witte et al., 2009) were used for this retrospective pooled study. Within our patient group, we included 21 medication-free subjects (18 males) between 22 and 56 years of age [mean age ( \pm SD), $30.3 \pm$ 7.9 years $]$ with social anxiety $(n=16)$ or panic disorder $(n=5)$. DSM-IV (Diagnostic and Statistical Manual of Mental Disorders, fourth revision) diagnosis was assessed by an experienced psychiatrist with the MINI International Neuropsychiatric Interview and the Spielberger State-Trait Anxiety Inventory on the day of the screening visit. Exclusion criteria covered comorbidity of depression or axis I disorders, history of alcohol or substance abuse, and any prior lifetime medication targeting the serotonergic system. Patients underwent two PET measurements, one before and one after at least 12 weeks of escitalopram treatment. However, for six subjects, PET scans after SSRI treatment were not available/included in the analysis (two voluntarily withdrew from the study, two were noncompliant with the medication intake, one because of alcohol abuse, and one because of excessive movement during the second PET scan), leaving 15 patients ( 12 males) with social anxiety $(n=11)$ or panic disorder $(n=4)$.

An additional 36 healthy controls ( 18 males) aged $20-46$ years [mean age ( $\pm \mathrm{SD}), 25.8 \pm 4.9$ years] were included that have been described in previous studies (Stein et al., 2008; Fink et al., 2009; Witte et al., 2009). Briefly, all female participants were measured with PET in the follicular phase of their menstrual cycle (Jovanovic et al., 2006), and additional exclusion criteria with respect to patients were any mental, neurological, or psychiatric disorders.

To ensure their physical healthy condition, patients and healthy subjects underwent a standard medical examination including electrocardiography, routine laboratory tests, and assessment of general physical and neurological status. Female participants were tested for pregnancy at the screening visit and before each PET measurement. All subjects were recruited via advertisement or from the outpatient department of the General Hospital of Vienna; they provided written informed consent at the screening visit and received reimbursement for their participation. This study was approved by the Ethics Committee of the Medical University of Vienna and the General Hospital of Vienna.

Treatment. After the first PET scan, each patient received an individual oral dose of escitalopram for a minimum duration of 12 weeks [mean
Table 1. Demographic characteristics of patients and healthy subjects

\begin{tabular}{lcc}
\hline & \multicolumn{2}{l}{ Sample demographics } \\
\cline { 2 - 3 } & Patients & Healthy controls \\
\hline Gender $(\mathrm{M} / \mathrm{F})$ & $18 / 3^{*}$ & $18 / 18$ \\
$\mathrm{BMI}\left(\mathrm{kg} / \mathrm{m}^{2}\right)$ & $23.9 \pm 3.5$ & $23.0 \pm 3.3$ \\
Cigarettes/day & $5.8 \pm 8.7$ & $3.0 \pm 4.7$ \\
Alcohol/week & $4.4 \pm 5.3$ & $5.06 \pm 5.2$ \\
STAl state & $44.5 \pm 7.1^{* *}$ & $32.4 \pm 7.1$ \\
STAl trait & $46.3 \pm 10.3^{* *}$ & $32.3 \pm 10.0$ \\
\hline
\end{tabular}

Data are given as mean $\pm S D$. Alcohol/week, Alcohol units per week = alcohol consumption (liter) $\times$ alcohol by volume ratio. M, Male; F, female; BMI, body mass index; STAl, Spielberger State-Trait Anxiety Inventory. ${ }^{*} p<0.01$; ${ }^{* *} p<0.001$, comparing patients with healthy subjects (two-tailed $\chi 2$ test, independent-samples $t$ test, as appropriate).

treatment duration $( \pm \mathrm{SD}), 105 \pm 24 \mathrm{~d}]$, where dosage was determined by an experienced psychiatrist ranging between 5 and $30 \mathrm{mg} / \mathrm{d}$ (for details, see Spindelegger et al., 2008). Thirteen of the 15 patients who completed the study received $10 \mathrm{mg} / \mathrm{d}$ escitalopram for the entire study duration. One patient did not respond to a dose of $10 \mathrm{mg} / \mathrm{d}$, thus dosage was increased to the maximum of $30 \mathrm{mg} / \mathrm{d}$. Because of weak clinical symptoms, one patient was treated with $5 \mathrm{mg} / \mathrm{d}$ for the entire study duration.

Based on previous work (Klein et al., 2007), blood samples were collected on the day of the second PET scan $\sim 6 \mathrm{~h}$ after escitalopram intake. Escitalopram plasma levels were determined by the Division of Neurochemistry at the University of Innsbruck, Austria. For technical reasons, plasma levels were only available from 12 patients, including the two subjects with a dosage of 5 and $30 \mathrm{mg} / \mathrm{d}$.

PET protocol. PET was performed at the Department of Nuclear Medicine of the Medical University of Vienna, Austria, using a GE Advance PET scanner (General Electric Medical Systems) as described previously (Lanzenberger et al., 2007). Briefly, the subject was placed in the scanner parallel to the orbitomeatal line using a laser-beam system. Tissue attenuation was measured in a 5 min transmission scan using a retractable ${ }^{68} \mathrm{Ge}$ ring source. The three-dimensional dynamic PET scan started simultaneously with the intravenous bolus injection of the radioligand [carbonyl- ${ }^{11} \mathrm{C}$ ]WAY-100635, which is suitable for the quantification of the $5-\mathrm{HT}_{1 \mathrm{~A}}$ receptor (Gunn et al., 1998). The radioligand was prepared as described previously (Wadsak et al., 2007) and injected in PBS [pH 7.4; mean injected dose $( \pm \mathrm{SD}), 375.9 \pm 36.4 \mathrm{MBq}$ ]. Each measurement consisted of 30 time frames, $15 \times 1$ and $15 \times 5$ min, yielding a total scanning duration of $90 \mathrm{~min}$. After scatter and attenuation correction, PET data were reconstructed using an iterative filtered back-projection algorithm (FORE+ITER), giving a final spatial resolution of $4.36 \mathrm{~mm}$ full-width at half-maximum at the center of the field of view (matrix, $128 \times 128 ; 35$ slices).

Regions of interest and tracer kinetic modeling. Preprocessing was performed in PMOD 2.95 (PMOD Technologies). To determine 5- $\mathrm{HT}_{1 \mathrm{~A}}$ autoreceptor binding in the DRN, a region of interest (ROI) comprising spheres of $4 \mathrm{~mm}$ diameter was defined manually in two slices of the original (non-normalized) summed PET image (Lanzenberger et al., 2007; Spindelegger et al., 2008; Sullivan et al., 2009). Correct ROI location was ensured using the coregistered magnetic resonance imaging scan. All PET records where then normalized to a tracer-specific template (Stein et al., 2008; Fink et al., 2009; Witte et al., 2009), and voxel-wise $5-\mathrm{HT}_{1 \mathrm{~A}}$ receptor maps within the stereotactic Montreal Neurological Institute (MNI) space were computed for assessment of heteroreceptors.

The $5-\mathrm{HT}_{1 \mathrm{~A}}$ receptor binding potential $\left[\mathrm{BP}_{\mathrm{ND}}\right.$ (Innis et al., 2007)] was quantified using the multilinear reference tissue model [MRTM2 (Ichise et al., 2003)] for both the DRN ROI and parametric 5-HT $1 \mathrm{~A}$ maps. Although similar to the simplified reference tissue model (Lammertsma and Hume, 1996), the MRTM2 has the advantage of fixing the clearance rate of the radiotracer from the reference region to the plasma $\left(\mathrm{k}_{2}^{\prime}\right)$, thus reducing the number of estimated parameters and providing more stable results, especially for voxel-wise analysis. Here, $\mathrm{k}_{2}^{\prime}$ was calculated from the insula and cerebellum [i.e., receptor-rich and -poor regions (Ichise et al., 2003; Varnas et al., 2004)], both taken from an automated anatomical labeling-based (Tzourio-Mazoyer et al., 2002) ROI atlas (Stein et al., 
Table 2. Average values and range of $5-H T_{1 A}$ binding potential $\left(B P_{N D}\right)$ for regions examined

\begin{tabular}{llll}
\hline & \multicolumn{2}{l}{ Average values and range of 5-HT ${ }_{1 \mathrm{~A}} \mathrm{BP}_{\mathrm{ND}}$} & \\
\cline { 2 - 4 } Region & Healthy controls & Patients before SSRI & Patients after SSRI \\
\hline DRN & $2.90 \pm 0.72(1.29-4.87)$ & $2.85 \pm 0.09(1.08-4.78)$ & $2.67 \pm 0.75(1.77-4.71)$ \\
Amygdala & $4.26 \pm 1.05(1.59-6.79)$ & $3.97 \pm 1.47(1.46-7.08)$ & $4.12 \pm 1.45(2.20-6.43)$ \\
Hippocampus & $4.22 \pm 1.00(1.52-6.68)$ & $3.92 \pm 1.62(1.23-6.76)$ & $3.99 \pm 1.60(1.81-6.50)$ \\
Insula & $4.94 \pm 0.94(1.90-7.33)$ & $4.52 \pm 1.26(1.96-6.24)$ & $4.68 \pm 1.05(3.29-6.81)$ \\
ACC & $3.91 \pm 0.86(1.31-5.88)$ & $3.56 \pm 0.98(1.62-5.00)$ & $3.68 \pm 0.78(2.84-5.47)$ \\
m0FC & $4.15 \pm 0.81(1.54-6.25)$ & $3.88 \pm 1.12(1.63-5.60)$ & $4.01 \pm 0.90(2.82-5.78)$ \\
Fusiform & $5.52 \pm 1.07(1.99-7.43)$ & $4.79 \pm 1.35(2.06-6.88)$ & $4.96 \pm 1.11(3.61-7.40)$ \\
\hline
\end{tabular}

Values have been averaged for left and right hemisphere. Data are given as mean $\pm \mathrm{SD}$ (minimum-maximum). The Kolmogorov-Smirnov test confirmed normal distribution of 5 - $\mathrm{HT} \mathrm{IA}_{\mathrm{A}} \mathrm{BP}_{\mathrm{ND}}$ within all regions for healthy controls and patients before and after treatment. ACC, Anterior cingulate cortex; Fusiform, fusiform gyrus; $\mathrm{mOFC}$, medial orbitofrontal cortex.

2008). The reference region was defined as cerebellar gray (excluding vermis), but because of recent concerns (Parsey et al., 2005; Hirvonen et al., 2007), 5- $\mathrm{HT}_{1 \mathrm{~A}} \mathrm{BP}_{\mathrm{ND}}$ was also quantified with the cerebellar white matter.

ROIs for the assessment of heteroreceptor binding were defined from group comparisons (1) anatomically with the ROI atlas (Stein et al., 2008) and (2) functionally as clusters with significant differences between patients before and after treatment. Thus, functional ROIs comprise a subpart of the anatomical areas. For post hoc analysis, additional regions were taken from the same ROI atlas (Stein et al., 2008). These included the bilateral amygdala; the hippocampus; the insulary, medial orbitofrontal, and anterior cingulate cortices, because of their involvement in anxiety disorders (Cannistraro and Rauch, 2003; Lanzenberger et al., 2007; Nash et al., 2008; Spindelegger et al., 2008), as well as the fusiform gyrus as a nonlimbic control region.

Statistical analysis. To evaluate the association of 5- $\mathrm{HT}_{1 \mathrm{~A}}$ binding between autoreceptors and heteroreceptors, a voxel-wise linear regression analysis was performed in SPM5 (Wellcome Trust Centre for Neuroimaging, London, UK; http://www.fil.ion.ucl.ac.uk/spm/) for each group separately (i.e., healthy subjects at baseline as well as patients before and after SSRI treatment). Here, the $\mathrm{BP}_{\mathrm{ND}}$ values of the DRN ROI served as the regressor, and the whole-brain voxel-wise $5-\mathrm{HT}_{1 \mathrm{~A}}$ binding maps served as the dependent variable, controlling for sex because of controversial results (Jovanovic et al., 2008; Stein et al., 2008 ). The resulting $t$ maps were then transformed into $R$ maps representing the correlation coefficient of the regression model $[p<0.05$, corrected for multiple comparisons using the false discovery rate (FDR)] with the VBM toolbox 5.1 (http://dbm.neuro.uni-jena.de/vbm/). To evaluate differences in regression slopes $\beta$ across study populations, an analysis of covariance was applied in SPM5 ( $p<0.01$, controlling for sex), which is equivalent to the following $t$ statistic (Howell, 2002):

$$
t=\frac{\beta_{1}-\beta_{2}}{S E\left(\beta_{1}-\beta_{2}\right)}
$$

where $\operatorname{SE}\left(\beta_{1}-\beta_{2}\right)$ is the pooled standard error. To assess group differences in correlation coefficients, $R$ values were extracted from voxel-wise maps of the regression analysis across anatomical and functional ROIs. Then, $R$ values were normalized $\left(R^{\prime}\right)$ using Fisher's $r$-to- $z$ transformation:

$$
R^{\prime}=0.5 \times \ln \left(\frac{1+R}{1-R}\right)
$$
Left is right.
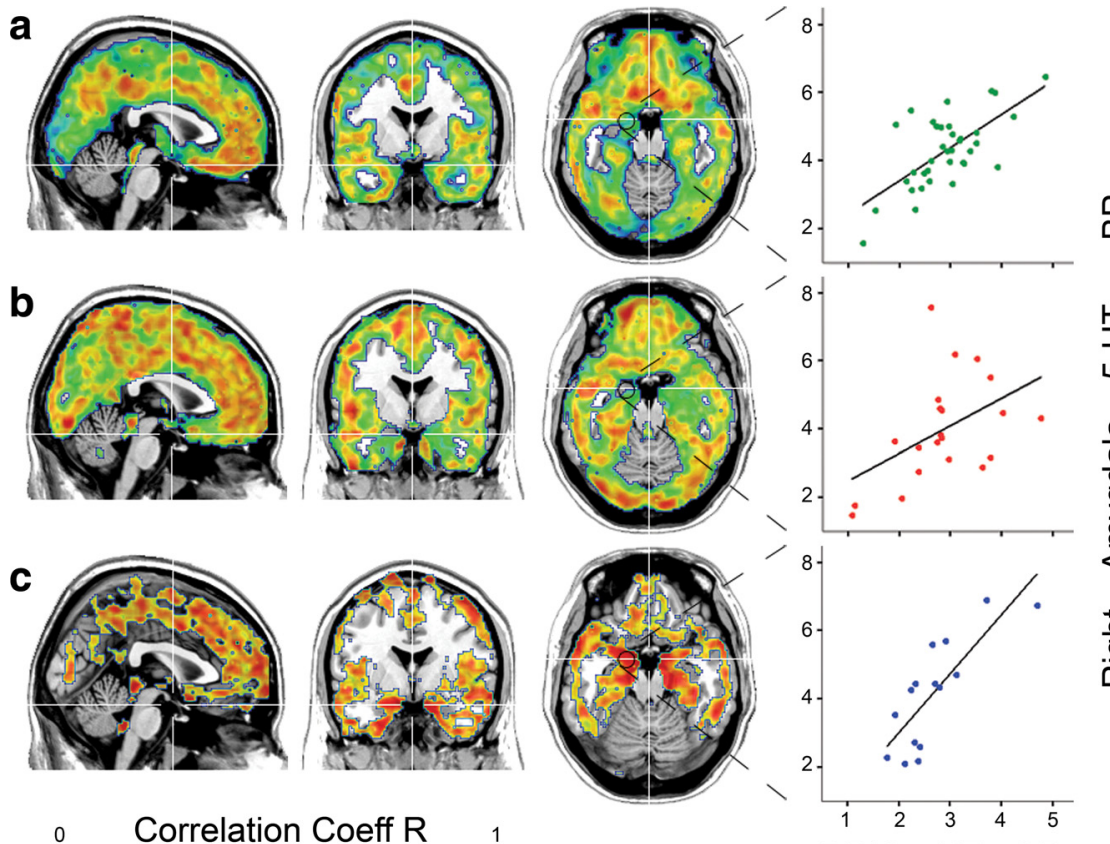

DRN 5-HT 1 A BPND

Figure 1. Voxel-wise maps representing correlation coefficients ( $p<0.05$, FDR-corrected) between DRN (autoreceptor) and heteroreceptor $5-\mathrm{HT}_{1 \mathrm{~A}} \mathrm{BP}_{\mathrm{ND}}$ within healthy subjects $(\boldsymbol{a})$ and anxiety disorder patients before $(\boldsymbol{b})$ and after $(\boldsymbol{c})$ escitalopram treatment. Exemplary regression lines (right) show the association between the DRN and anatomically defined (Stein et al., 2008) right amygdala 5-HT ${ }_{1 \mathrm{~A}} \mathrm{BP}_{\mathrm{ND}}$ for each group (see Table 3 for $R, \beta$, and $p$ values). Crosshair is at MNI coordinates $x, y, z: 1,-1,-19 \mathrm{~mm}$.

and a $Z$ statistic was calculated between regional correlation coefficients of the study populations (Howell, 2002):

$$
Z=\frac{R_{1}^{\prime}-R_{2}^{\prime}}{\sqrt{\frac{1}{n_{1}-3}+\frac{1}{n_{2}-3}}}
$$

where $n_{1}$ and $n_{2}$ represent the sample size of each group. The adapted version for paired samples is given by Steiger (1980). Considering their different explanatory value, we report both regression and correlation coefficients. Whereas $\beta$ gives the slope of the regression line (i.e., the change in the dependent variable for each unit change in the independent variable), $R$ (and $R^{2}$ ) describe how much of the variance of the dependent variable can be explained by the independent variable. Taking into account multiple comparisons among intercorrelated data, FDR correction was applied for voxel-wise comparisons of regression coefficients $(t$ values) and Bonferroni-Holm adjustment was applied when comparing correlation coefficients ( $Z$ values) for regions with significant differences between patients before and after treatment (see Table 4).

In addition to our primary hypothesis of evaluating $5-\mathrm{HT}_{1 \mathrm{~A}}$ associations between autoreceptors and heteroreceptors, we tested whether this 

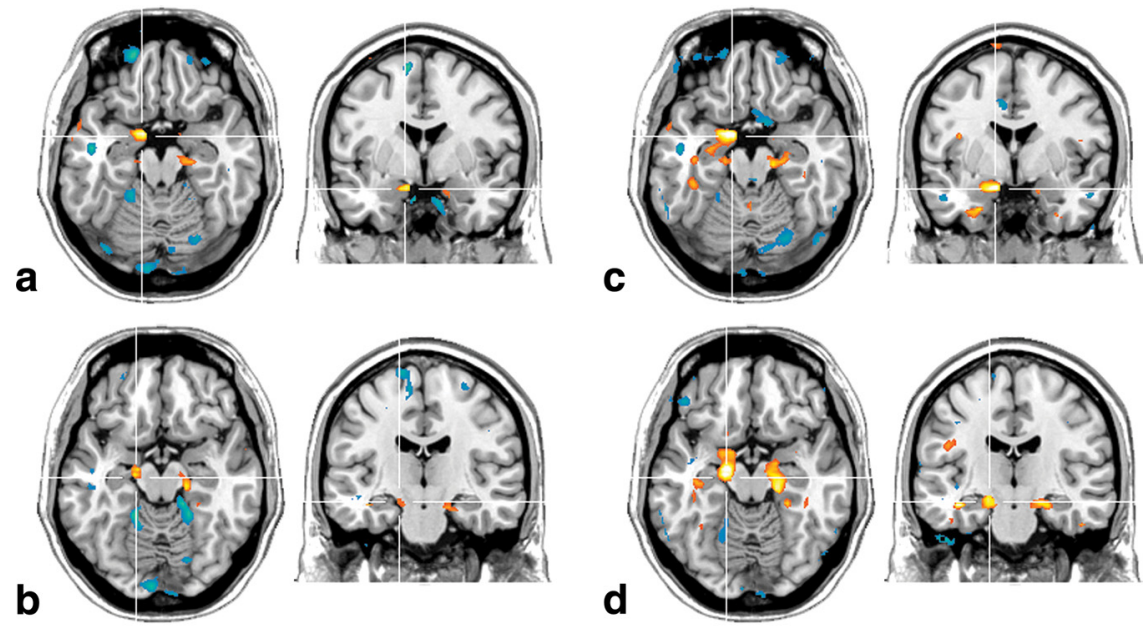

0

T-values

$\pm 5$

Figure 2. SSRI-induced changes in the regression between $5-\mathrm{HT}_{1 \mathrm{~A}}$ autoreceptor binding in the $\mathrm{DRN}$ and heteroreceptor $5-\mathrm{HT}_{1 \mathrm{~A}}$ $\mathrm{BP}_{\mathrm{ND}}(t>2.46 ; p<0.01)$ within the amygdala $(\boldsymbol{a}, \boldsymbol{c})$ and hippocampus $(\boldsymbol{b}, \boldsymbol{d})$. Comparisons were performed between anxiety disorder patients before and after escitalopram medication $(\boldsymbol{a}, \boldsymbol{b})$ as well as between treated patients and healthy subjects $(\boldsymbol{c}, \boldsymbol{d})$. Note that for the comparison given in cand $\boldsymbol{d}$ (medicated patients vs healthy controls), the differences in the regression slope were smaller but reached higher significance for the amygdala (Tables 3, 4). Crosshair is at MNI coordinates $x, y, z: \boldsymbol{a}, \boldsymbol{c}, 12,-1,-19$ $\mathrm{mm} ; \boldsymbol{b}, \boldsymbol{d}, 16,-17,-15 \mathrm{~mm}$. Left is right.

Table 3. Association between DRN (autoreceptor) and heteroreceptor 5- $\mathrm{HT} \mathrm{TA}_{1 \mathrm{~A}} \mathrm{BP}_{\mathrm{ND}}$ representing correlation coefficients $R$ and regression slopes $\beta$ for each group separately

\begin{tabular}{|c|c|c|c|c|c|}
\hline \multirow[b]{3}{*}{ Region } & \multicolumn{3}{|c|}{ Anatomical ROI } & \multirow{2}{*}{\multicolumn{2}{|c|}{$\begin{array}{l}\text { Functional R0I } \\
\text { Patients }\end{array}$}} \\
\hline & \multirow[b]{2}{*}{$\begin{array}{l}\text { Healthy } \\
\text { controls }\end{array}$} & \multicolumn{2}{|c|}{ Patients } & & \\
\hline & & $\begin{array}{l}\text { Before } \\
\text { SSRI }\end{array}$ & $\begin{array}{l}\text { After } \\
\text { SSRI }\end{array}$ & $\begin{array}{l}\text { Before } \\
\text { SSRI }\end{array}$ & $\begin{array}{l}\text { After } \\
\text { SSRI }\end{array}$ \\
\hline \multicolumn{6}{|c|}{ Correlation coefficient $R$} \\
\hline \multicolumn{6}{|c|}{ Amygdala } \\
\hline Right & $0.56^{* * *}$ & $0.5^{*}$ & $0.79^{* * *}$ & $0.46^{*}$ & $0.88^{* * *}$ \\
\hline Left & $0.55^{* * *}$ & $0.51^{*}$ & $0.73^{* *}$ & $0.49^{*}$ & $0.9^{* * *}$ \\
\hline \multicolumn{6}{|c|}{ Hippocampus } \\
\hline Right & $0.45^{* *}$ & $0.53^{*}$ & $0.73^{* *}$ & $0.47^{*}$ & $0.82^{* * *}$ \\
\hline Left & $0.47^{* *}$ & $0.49 *$ & $0.7^{* *}$ & $0.5^{*}$ & $0.85^{* * *}$ \\
\hline \multicolumn{6}{|c|}{ Regression slope $\beta$} \\
\hline \multicolumn{6}{|c|}{ Amygdala } \\
\hline Right & $0.99^{* * *}$ & $0.87^{*}$ & $1.91^{* * *}$ & $0.8^{*}$ & $2.74^{* * *}$ \\
\hline Left & $1.07^{* * *}$ & $0.9^{*}$ & $1.5^{* *}$ & $1^{*}$ & $2.61^{* * *}$ \\
\hline \multicolumn{6}{|c|}{ Hippocampus } \\
\hline Right & $0.86^{* *}$ & $1.04^{*}$ & $2^{* *}$ & $0.78^{*}$ & $2.5^{* * *}$ \\
\hline Left & $0.97^{* *}$ & $1.23^{*}$ & $1.92^{* *}$ & $1^{*}$ & $2.7^{* * *}$ \\
\hline
\end{tabular}

ROls were defined (1) anatomically (Stein et al., 2008) [ROl atlas-based (Tzourio-Mazoyer et al., 2002)] and (2) functionally comprising clusters with significant differences between patients before and after treatment ${ }^{* *}$ (see Fig. $2 a, b) .{ }^{*} p<0.05 ;{ }^{* *} p<0.01 ;{ }^{* * *} p<0.001$, all parameters survive correction for multiple comparisons $(p<0.05$ FDR).

effect as well as group differences are limited to connections of the DRN to projection areas or also exist between regions with heteroreceptors. Thus, post hoc correlation analyses were performed between ROIs expressing $5-\mathrm{HT}_{1 \mathrm{~A}}$ heteroreceptors (amygdala; hippocampus; insula; medial orbitofrontal and anterior cingulate cortices; fusiform gyrus). This subsequent analysis of regional 5- $\mathrm{HT}_{1 \mathrm{~A}} \mathrm{BP}_{\mathrm{ND}}$ and correlations with escitalopram plasma levels were calculated in SPSS 15.0 (SPSS) and Matlab R2006b (The Mathworks). All statistical tests were two-tailed.

\section{Results}

As described previously by our group (Spindelegger et al., 2008), after escitalopram medication both state $(44.8 \pm 7.7$ vs $37.5 \pm 7.2)$

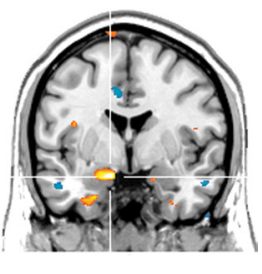

and trait $(47.1 \pm 11.6$ vs $38.9 \pm 10.6)$ anxiety levels of patients were significantly lower $(p<0.001)$. Demographic sample characteristics are given in Table 1, whereas no significant correlations have been found between regional 5- $\mathrm{HT}_{1 \mathrm{~A}} \mathrm{BP}_{\mathrm{ND}}$ and demographic variables. An overview of the range of $5-\mathrm{HT}_{1 \mathrm{~A}} \mathrm{BP}_{\mathrm{ND}}$ values are given in Table 2, but for an evaluation of regional $5-\mathrm{HT}_{1 \mathrm{~A}}$ $\mathrm{BP}_{\mathrm{ND}}$, the reader is referred to previous studies (Lanzenberger et al., 2007; Spindelegger et al., 2008). The amount of S-citalopram in plasma ranged between 4 and $35 \mathrm{ng} / \mathrm{ml}$ (mean $\pm \mathrm{SD}, 14.0 \pm 8.3 \mathrm{ng} / \mathrm{ml}$ ).

\section{Association of $5-\mathrm{HT}_{1 \mathrm{~A}} \mathrm{BP}_{\mathrm{ND}}$ between autoreceptors and heteroreceptors in healthy subjects}

For healthy controls $(n=36)$, the $5-\mathrm{HT}_{1 \mathrm{~A}}$ receptor $\mathrm{BP}_{\mathrm{ND}}$ of the DRN was positively correlated with heteroreceptor binding in most cortical regions, being strongest within the insula, cingulate cortex, and frontal areas (Fig. 1a). The correlation was weaker within the occipital cortex and subcortical regions of the amygdala and hippocampus. The only negative correlations were found $(R<0.5)$ in the cerebellar vermis. There was no significant correlation in the cerebellar cortex, the striatum, and the thalamus. In general, regression lines were steeper in women than in men $(p<0.05)$, especially within the orbitofrontal cortex and the insula, but not within the DRN, amygdala, or hippocampus.

\section{Association of 5- $\mathrm{HT}_{1 \mathrm{~A}} \mathrm{BP}_{\mathrm{ND}}$ between autoreceptors and} heteroreceptors in untreated patients

Similar to healthy controls, unmedicated anxiety disorder patients $(n=21)$ showed weak associations in subcortical regions. In general, correlations were stronger, especially in the occipital cortex, but the overall correlation pattern was topologically less structured (Fig. 1b). However, significant differences in the regression slopes between untreated patients and healthy controls were found only within the right fusiform, lingual, and inferior occipital cortices $(p<0.01)$. In contrast, healthy subjects showed greater regression coefficients in the middle cingulate cortex and the bilateral inferior orbitofrontal cortex $(p<0.01)$.

Association of 5- $\mathrm{HT}_{1 \mathrm{~A}} \mathrm{BP}_{\mathrm{ND}}$ between autoreceptors and heteroreceptors in patients after escitalopram treatment After patients were continuously treated with escitalopram $(n=$ 15), the correlations of 5- $\mathrm{HT}_{1 \mathrm{~A}} \mathrm{BP}_{\mathrm{ND}}$ between autoreceptors and heteroreceptors strengthened in cortical and even more within limbic subcortical regions, but areas with lower correlations no longer reached statistical significance (Fig. 1c). Direct comparison of anxiety disorder patients before and after medication revealed group differences at the subcortical level (Fig. 2a, $b$; Tables $3,4)$. More precisely, correlation coefficients between $5-\mathrm{HT}_{1 \mathrm{~A}}$ autoreceptor and heteroreceptor $\mathrm{BP}_{\mathrm{ND}}$ were higher $\left(R^{2}\right.$ : before SSRI, $0.24-0.28$ vs after SSRI, $0.49-0.62)$ and regression lines were steeper $(\beta=0.78-1.23$ vs $1.5-2.74 ; p<0.01)$ after treatment for the amygdala and hippocampus in both hemispheres. Using a functional ROI definition, these differences in the association were even higher $\left(R^{2}=0.21-0.25\right.$ vs $0.72-0.81 ; p<$ 
Table 4. Group differences in the association between the DRN and heteroreceptor $5-\mathrm{HT}_{1 \mathrm{~A}} \mathrm{BP}_{\mathrm{ND}}$

\begin{tabular}{|c|c|c|c|c|c|c|}
\hline \multirow[b]{3}{*}{ Region } & \multicolumn{6}{|c|}{ Functional ROI peak voxel } \\
\hline & \multicolumn{3}{|c|}{ Patients after versus before SSRI } & \multicolumn{3}{|c|}{ Patients after SSRI versus healthy controls } \\
\hline & MNI (mm) & $t$ value & $Z$ value & $\operatorname{MNI}(\mathrm{mm})$ & $t$ value & $Z$ value \\
\hline Right & $12,0,-20$ & $4.98^{* * *}$ & $2.78^{* * \#}$ & $16,0,-20$ & $5.78^{* * * \#}$ & $3.38^{* * * \#}$ \\
\hline Left & $-16,-2,-22$ & $2.76^{* *}$ & $2.62^{* * \#}$ & $-18,-2,-22$ & $3.01^{* *}$ & $2.61^{* * \#}$ \\
\hline \multicolumn{7}{|c|}{ Hippocampus } \\
\hline
\end{tabular}

ROIs were defined functionally as clusters where patients showed significantly steeper regression slopes after treatment** (see Fig. 2 ). $t$ and $Z$ values of these functional ROIs represent peak differences in the regression slope $\beta$ and correlation coefficient $R$, respectively, when comparing patients before and after escitalopram medication (see Fig. $2 a, b)$ as well as between treated patients and healthy subjects (see Fig. $2 c, d)$. ${ }^{*} p<0.05$; ${ }^{* *} p<0.01$; ${ }^{* * *} p<0.001$; ${ }^{*}$ withstanding correction for multiple comparisons (FDR and Bonferroni-Holm for $t$ and $Z$ values, respectively).

0.05-0.001), and the amygdala also survived correction for multiple comparisons. Hence, for the amygdala and hippocampus, the variability of $5-\mathrm{HT}_{1 \mathrm{~A}}$ heteroreceptor binding explained through $5-\mathrm{HT}_{1 \mathrm{~A}} \mathrm{BP}_{\mathrm{ND}}$ of the DRN almost tripled after SSRI administration. Furthermore, the increased regression coefficients indicate that changes in $5-\mathrm{HT}_{1 \mathrm{~A}} \mathrm{BP}_{\mathrm{ND}}$ of the DRN have a 1.5-3.4 times greater effect on heteroreceptors after escitalopram medication (Table 3 ).

Comparing patients after escitalopram medication with healthy subjects, differences in correlation and regression coefficients were smaller but reached greater significance $(p<0.01)$ (Fig. 2c,d; Tables 3, 4). Furthermore, steeper regression lines between treated patients and healthy subjects were found for the subgenual part of the anterior cingulate cortex and the bilateral insula, nucleus accumbens, and fusiform gyrus $(p<0.01)$. In contrast, treated patients had less steep regression slopes within occipital and cerebellar cortices $(p<0.01)$ than healthy subjects; however, this was less marked than for the comparison with untreated patients (Fig. $2 a-d$ )

Importantly, comparing only those patients where pretreatment and posttreatment PET scans are available or using cerebellar white matter as a reference region did not change the findings of this study. Similarly, the results remained stable when investigating only patients with social anxiety disorder. Also, tracer deliver $\left(R 1=K 1_{\mathrm{ROI}} / K 1_{\mathrm{Ref}}\right)$ and washout $(k 2)$ rates did not differ significantly between any of the three groups (data not shown). Notably, controlling for sex effects improved the regression model and group comparisons.

\section{Post hoc data analysis}

Subsequent correlation analysis was performed to assess whether $5-\mathrm{HT}_{1 \mathrm{~A}}$ receptor associations between two regions are limited to connections between autoreceptors and heteroreceptors or also exist for areas expressing only heteroreceptors. Indeed, $5-\mathrm{HT}_{1 \mathrm{~A}}$ $\mathrm{BP}_{\mathrm{ND}}$ between regions with heteroreceptors (amygdala; hippocampus; insulary, medial orbitofrontal, and anterior cingulate cortices; fusiform gyrus) were highly correlated in healthy subjects (Pearson's $r=0.59-0.96 ; p<0.001$ ) as well as in patients before $(r=0.73-0.98 ; p<0.001)$ and after $(r=0.57-0.96$; $p<$ $0.001)$ treatment. However, direct comparisons revealed no significant differences in this correlation between any of the heteroreceptor areas neither between healthy subjects and patients nor when comparing patients before and after SSRI treatment. Furthermore, we found a negative correlation of the SSRI-induced change in $5-\mathrm{HT}_{1 \mathrm{~A}} \mathrm{BP}_{\mathrm{ND}}$ with escitalopram plasma levels in the DRN (Spearman's $\rho=-0.58, p<0.05$ ), but not within the amygdala or the hippocampus.

\section{Discussion}

This work extends previous findings of positive correlations of $5-\mathrm{HT}_{1 \mathrm{~A}}$ receptor binding between brain areas in healthy human subjects. More importantly, this is the first study showing an increased association between DRN autoreceptor to amygdalar and hippocampal heteroreceptor $5-\mathrm{HT}_{1 \mathrm{~A}}$ binding in patients with anxiety disorders after prolonged escitalopram treatment.

\section{Association of 5- $\mathrm{HT}_{1 \mathrm{~A}} \mathrm{BP}_{\mathrm{ND}}$ between autoreceptors and heteroreceptors in healthy subjects}

Consistent with previous observations (Rabiner et al., 2002; Borg et al., 2006; Drevets et al., 2007), we found widespread positive correlations between $5-\mathrm{HT}_{1 \mathrm{~A}} \mathrm{BP}_{\mathrm{ND}}$ in the $\mathrm{DRN}$ and projection areas in healthy subjects. 5- $\mathrm{HT}_{1 \mathrm{~A}}$ autoreceptors inhibit tonic firing activity of serotonergic neurons (Hajos et al., 2001; Evans et al., 2008) and hence decrease 5-HT release into the synaptic cleft (Parsons et al., 2001; Bundgaard et al., 2006). Additional studies reported inverse relationships between serotonin synthesis and heteroreceptor binding (Frey et al., 2008) and behavioral responses (Cowen et al., 1996; Heslop and Curzon, 1999). This suggests that low synaptic 5-HT levels, caused by a high level of $5-\mathrm{HT}_{1 \mathrm{~A}}$ autoreceptors, lead to a compensatory upregulation of $5-\mathrm{HT}_{1 \mathrm{~A}}$ heteroreceptors. Our observation of almost exclusively positive correlations between autoreceptors and heteroreceptors also supports this but requires confirmation since individual serotonin levels were not measurable in this study.

\section{Association of 5- $\mathrm{HT}_{1 \mathrm{~A}} \mathrm{BP}_{\mathrm{ND}}$ between autoreceptors and heteroreceptors in untreated patients}

In contrast to healthy subjects, it seems that untreated patients with anxiety disorders feature a less area-specifically structured and rather disorganized correlation pattern with, for example, greater correlation and regression coefficients in the occipital cortex. On the other hand, patients had lower regression coefficients in the orbitofrontal cortex, a region with decreased functional connectivity to the amygdala in anxiety disorders (Monk et al., 2008), indicating alterations of the entire 5-HT network in the patient group.

\section{Association of 5- $\mathrm{HT}_{1 \mathrm{~A}} \mathrm{BP}_{\mathrm{ND}}$ between autoreceptors and heteroreceptors in patients after escitalopram treatment} Continuous escitalopram treatment strengthened the associations in all brain regions with marked effects in the amygdala and hippocampus. Considering the disorganization in untreated patients, this suggests an impaired homeostatic mechanism to adapt serotonergic neurotransmission on a network level. Although we cannot prove a causal relationship, SSRIs seem to reinforce these 
adaptive processes by enhancing the regulatory influence of the DRN onto regions specifically involved in anxiety disorders (Gross et al., 2002; Gordon et al., 2005; Harmer et al., 2006). This is also consistent with previous results from anxiety disorder patients (Lanzenberger et al., 2007; Spindelegger et al., 2008) and a similar hypothesis of disturbed homeostatic mechanisms in major depression (Arango et al., 2001). Additionally, our findings possibly substantiate the amygdala hyperactivation in anxiety disorders (Harmer et al., 2006) and depression (Sheline et al., 2001) resolved by SSRIs.

Our interregional approach underlines the neuroplasticity of the serotonergic system that occurs well coordinated on a network level. This might be an important issue within treatment (Azmitia, 1999; Michelsen et al., 2008) considering that the serotonin transporter (Frodl et al., 2004) and the serotonin-1A, -1B, and $-2 \mathrm{~A}$ receptor subtypes regulate neurogenesis within the hippocampus (Banasr et al., 2004). Conversely, stress decreases and SSRI treatment increases the neurogenesis in this area (Dranovsky and Hen, 2006; Wu and Castren, 2009), which is further indicated as a key action site of $5-\mathrm{HT}_{1 \mathrm{~A}}$ receptors in anxiety processing (Gross et al., 2002; Gordon et al., 2005).

The investigation of network effects is also encouraged by the regulation of conditioned fear through the balance between serotonin-1A and $-2 \mathrm{~A}$ receptor activation (Michelsen et al., 2008). Although network changes might represent a central issue in antidepressant treatment (El Mansari et al., 2005), the driving factors are still far from understood. Previous studies in rats demonstrated $5-\mathrm{HT}_{1 \mathrm{~A}}$ receptor-mediated feedback loops from the medial prefrontal cortex (Casanovas et al., 1999; Sharp et al., 2007) and decreased responsiveness of amygdalar 5-HT $\mathrm{HA}_{1 \mathrm{~A}}$ heteroreceptors after chronic SSRI treatment (Bosker et al., 2001). Together with desensitization of the raphe nuclei, these studies are consistent with our finding of enhanced 5- $\mathrm{HT}_{1 \mathrm{~A}}$ correlations between amygdala and DRN after sustained escitalopram medication. In contrast, within rats no differences in $5-\mathrm{HT}_{1 \mathrm{~A}}$ autoreceptor or heteroreceptor binding were observed after chronic citalopram treatment, although changes in $5-\mathrm{HT}_{1 \mathrm{~A}}$ receptor-Gprotein coupling were found (Moulin-Sallanon et al., 2009). Therefore, it cannot be excluded that our results might be related to shifts in $5-\mathrm{HT}_{1 \mathrm{~A}}$ receptor affinity rather than density, which nevertheless implicates a functional change instead of a structural one. Such alterations in receptor affinity might also include changes at the transcriptional level (Le Poul et al., 2000). Indeed, chronic SSRI administration increased cortical and striatal 5- $\mathrm{HT}_{1 \mathrm{~B}}$ mRNA levels, whereas 5- $\mathrm{HT}_{1 \mathrm{~A}}$ mRNA decreases (and receptor desensitizations) were found only in the DRN (Le Poul et al., 2000), further underlining the regional specificity of SSRI effects.

It is not surprising that application of the cerebellar white matter as reference did not change our findings since it is used for quantification of both autoreceptors and heteroreceptors. Accordingly, changes or group differences in nonspecific binding (or any other factor influencing $5-\mathrm{HT}_{1 \mathrm{~A}}$ globally) only shifts the regression line but would not alter correlation or regression coefficients.

\section{Post hoc data analysis}

Consistent with previous studies, we found high correlations between brain areas expressing only heteroreceptors. Interestingly, none of these heteroreceptor associations differed across groups nor changed after escitalopram treatment, indicating that adaptive mechanisms are mainly driven by $5-\mathrm{HT}_{1 \mathrm{~A}}$ autoreceptors. This is further underlined by our observation that SSRI-induced changes in 5- $\mathrm{HT}_{1 \mathrm{~A}}$ autoreceptor but not heteroreceptor binding correlated with escitalopram plasma levels. Considering that blood sampling was done slightly after the peak escitalopram concentration is reached, concentrations of our patient sample correspond to previously reported values (Sogaard et al., 2005); however, local escitalopram levels in different brain areas remain unknown. Our findings are in line with previous studies, suggesting that $5-\mathrm{HT}_{1 \mathrm{~A}}$ receptors within the DRN (Czesak et al., 2006; Fisher et al., 2006; Michelsen et al., 2008; Fakra et al., 2009; Richardson-Jones et al., 2010), rather than local heteroreceptors, are the key component for the modulation of complex autonomic functions.

\section{Limitations}

One issue is that we could not differentiate between autoreceptors and heteroreceptors within the raphe nuclei since $\left[\right.$ carbonyl- ${ }^{11} \mathrm{C}$ ] WAY-100635 binds to both. However, considering that $80-100 \%$ are 5-HT neurons in the DRN (Hornung, 2010), an exact determination of the proportion of $5-\mathrm{HT}_{1 \mathrm{~A}}$ autoreceptors is unlikely to change our main findings.

Another limitation is the small number of panic disorder patients included in this study. Thus, additional work is required to evaluate associations of 5- $\mathrm{HT}_{1 \mathrm{~A}}$ binding specifically in panic disorder. However, the inclusion of these patients improved the regression model, and considering consistent deficiencies in regional 5- $\mathrm{HT}_{1 \mathrm{~A}}$ binding within social anxiety (Lanzenberger et al., 2007) and panic disorder (Nash et al., 2008), we would expect similar changes on a network level.

Furthermore, this study was not able to evaluate sex differences in anxiety disorder patients since the patient group comprised only three women. Considering that regression coefficients of 5- $\mathrm{HT}_{1 \mathrm{~A}}$ autoreceptor-to-heteroreceptor binding were greater in healthy women than in men, the higher incidence for anxiety disorders in women (Becherer, 2008), and the discrepancy of sex differences in regional 5- $\mathrm{HT}_{1 \mathrm{~A}}$ receptor bindings (Jovanovic et al., 2008; Stein et al., 2008), future studies should include more patients with an equal distribution of male and female subjects to assess sex differences within SSRI treatment.

\section{Conclusions}

To summarize, this study is the first to demonstrate an enhanced association of 5- $\mathrm{HT}_{1 \mathrm{~A}}$ autoreceptor-to-heteroreceptor binding between the DRN with the amygdala and hippocampus in anxiety disorder patients after prolonged escitalopram treatment. Our results underline the regional specificity of SSRIs and the central role of the DRN as prime regulatory area. Hence, the evaluation of neurotransmitter systems on a network level potentially provides important complementary information to regional receptor levels.

\section{References}

Akimova E, Lanzenberger R, Kasper S (2009) The serotonin-1A receptor in anxiety disorders. Biol Psychiatry 66:627-635.

Arango V, Underwood MD, Boldrini M, Tamir H, Kassir SA, Hsiung S-C, Chen JJ-X, Mann JJ (2001) Serotonin 1A receptors, serotonin transporter binding and serotonin transporter mRNA expression in the brainstem of depressed suicide victims. Neuropsychopharmacology 25:892-903.

Azmitia EC (1999) Serotonin neurons, neuroplasticity, and homeostasis of neural tissue. Neuropsychopharmacology 21:33S-45S.

Banasr M, Hery M, Printemps R, Daszuta A (2004) Serotonin-induced increases in adult cell proliferation and neurogenesis are mediated through different and common 5-HT receptor subtypes in the dentate gyrus and the subventricular zone. Neuropsychopharmacology 29:450-460.

Bandelow B, Zohar J, Hollander E, Kasper S, Moller HJ (2002) World Fed- 
eration of Societies of Biological Psychiatry (WFSBP) guidelines for the pharmacological treatment of anxiety, obsessive-compulsive and posttraumatic stress disorders. World J Biol Psychiatry 3:171-199.

Becherer A (2008) The molecular background of sex differences in depressive disorders: still an enigma. Eur J Nucl Med Mol Imaging 35:2156-2158.

Blier P, De Montigny C (1983) Electrophysiological investigations on the effect of repeated zimelidine administration on serotonergic neurotransmission in the rat. J Neurosci 3:1270-1278.

Blier P, de Montigny C (1999) Serotonin and drug-induced therapeutic responses in major depression, obsessive-compulsive and panic disorders. Neuropsychopharmacology 21:91S-98S.

Blier P, Pineyro G, el Mansari M, Bergeron R, de Montigny C (1998) Role of somatodendritic 5-HT autoreceptors in modulating 5-HT neurotransmission. Ann N Y Acad Sci 861:204-216.

Borg J, Andree B, Lundberg J, Halldin C, Farde L (2006) Search for correlations between serotonin 5-HT1A receptor expression and cognitive functions-a strategy in translational psychopharmacology. Psychopharmacology 185:389-394.

Bosker FJ, Cremers TI, Jongsma ME, Westerink BH, Wikstrom HV, den Boer JA (2001) Acute and chronic effects of citalopram on postsynaptic 5-hydroxytryptamine(1A) receptor-mediated feedback: a microdialysis study in the amygdala. J Neurochem 76:1645-1653.

Bundgaard C, Larsen F, Jorgensen M, Gabrielsson J (2006) Mechanistic model of acute autoinhibitory feedback action after administration of SSRIs in rats: application to escitalopram-induced effects on brain serotonin levels. Eur J Pharm Sci 29:394-404.

Burghardt NS, Bush DE, McEwen BS, LeDoux JE (2007) Acute selective serotonin reuptake inhibitors increase conditioned fear expression: blockade with a 5-HT(2C) receptor antagonist. Biol Psychiatry 62:1111-1118.

Cannistraro PA, Rauch SL (2003) Neural circuitry of anxiety: evidence from structural and functional neuroimaging studies. Psychopharmacol Bull $37: 8-25$.

Casanovas JM, Hervas I, Artigas F (1999) Postsynaptic 5-HT1A receptors control 5-HT release in the rat medial prefrontal cortex. Neuroreport 10:1441-1445.

Cowen PJ, Clifford EM, Walsh AES, Williams C, Fairburn CG (1996) Moderate dieting causes 5-HT2C receptor supersensitivity. Psychol Med 26:1155-1159.

Czesak M, Lemonde S, Peterson EA, Rogaeva A, Albert PR (2006) Cellspecific repressor or enhancer activities of Deaf- 1 at a serotonin 1A receptor gene polymorphism. J Neurosci 26:1864-1871.

Dawson LA, Nguyen HQ, Smith DI, Schechter LE (2000) Effects of chronic fluoxetine treatment in the presence and absence of $(+/-)$ pindolol: a microdialysis study. Br J Pharmacol 130:797-804.

Dranovsky A, Hen R (2006) Hippocampal neurogenesis: regulation by stress and antidepressants. Biol Psychiatry 59:1136-1143.

Drevets WC, Frank E, Price JC, Kupfer DJ, Greer PJ, Mathis C (2000) Serotonin type-1A receptor imaging in depression. Nucl Med Biol 27:499-507.

Drevets WC, Thase ME, Moses-Kolko EL, Price J, Frank E, Kupfer DJ, Mathis C (2007) Serotonin-1A receptor imaging in recurrent depression: replication and literature review. Nucl Med Biol 34:865-877.

El Mansari M, Sanchez C, Chouvet G, Renaud B, Haddjeri N (2005) Effects of acute and long-term administration of escitalopram and citalopram on serotonin neurotransmission: an in vivo electrophysiological study in rat brain. Neuropsychopharmacology 30:1269-1277.

Evans AK, Reinders N, Ashford KA, Christie IN, Wakerley JB, Lowry CA (2008) Evidence for serotonin synthesis-dependent regulation of in vitro neuronal firing rates in the midbrain raphe complex. Eur J Pharmacol 590:136-149.

Fakra E, Hyde LW, Gorka A, Fisher PM, Munoz KE, Kimak M, Halder I, Ferrell RE, Manuck SB, Hariri AR (2009) Effects of HTR1A C(-1019)G on amygdala reactivity and trait anxiety. Arch Gen Psychiatry 66:33-40.

Fink KB, Gothert M (2007) 5-HT receptor regulation of neurotransmitter release. Pharmacol Rev 59:360-417.

Fink M, Wadsak W, Savli M, Stein P, Moser U, Hahn A, Mien LK, Kletter K, Mitterhauser M, Kasper S, Lanzenberger R (2009) Lateralization of the serotonin-1A receptor distribution in language areas revealed by PET. Neuroimage 45:598-605.

Fisher PM, Meltzer CC, Ziolko SK, Price JC, Moses-Kolko EL, Berga SL,
Hariri AR (2006) Capacity for 5-HT1A-mediated autoregulation predicts amygdala reactivity. Nat Neurosci 9:1362-1363.

Frey BN, Rosa-Neto P, Lubarsky S, Diksic M (2008) Correlation between serotonin synthesis and 5-HT1A receptor binding in the living human brain: a combined alpha-[11C]MT and [18F]MPPF positron emission tomography study. Neuroimage 42:850-857.

Frodl T, Meisenzahl EM, Zill P, Baghai T, Rujescu D, Leinsinger G, Bottlender R, Schüle C, Zwanzger P, Engel RR, Rupprecht R, Bondy B, Reiser M, Möller HJ (2004) Reduced hippocampal volumes associated with the long variant of the serotonin transporter polymorphism in major depression. Arch Gen Psychiatry 61:177-183.

Gordon JA, Hen R (2004) The serotonergic system and anxiety. Neuromol Med 5:27-40.

Gordon JA, Lacefield CO, Kentros CG, Hen R (2005) State-dependent alterations in hippocampal oscillations in serotonin 1A receptor-deficient mice. J Neurosci 25:6509-6519.

Gross C, Zhuang X, Stark K, Ramboz S, Oosting R, Kirby L, Santarelli L, Beck S, Hen R (2002) Serotonin1A receptor acts during development to establish normal anxiety-like behaviour in the adult. Nature 416:396-400.

Gunn RN, Sargent PA, Bench CJ, Rabiner EA, Osman S, Pike VW, Hume SP, Grasby PM, Lammertsma AA (1998) Tracer kinetic modeling of the 5-HT1A receptor ligand [carbonyl-11C]WAY-100635 for PET. Neuroimage 8:426-440.

Hajos M, Hoffmann WE, Tetko IV, Hyland B, Sharp T, Villa AE (2001) Different tonic regulation of neuronal activity in the rat dorsal raphe and medial prefrontal cortex via 5-HT(1A) receptors. Neurosci Lett 304:129-132.

Harmer CJ, Mackay CE, Reid CB, Cowen PJ, Goodwin GM (2006) Antidepressant drug treatment modifies the neural processing of nonconscious threat cues. Biol Psychiatry 59:816-820.

Heslop KE, Curzon G (1999) Effect of reserpine on behavioural responses to agonists at 5-HT1A, 5-HT1B, 5-HT2A, and 5-HT2C receptor subtypes. Neuropharmacology 38:883-891.

Hirvonen J, Kajander J, Allonen T, Oikonen V, Nagren K, Hietala J (2007) Measurement of serotonin 5-HT1A receptor binding using positron emission tomography and [carbonyl-(11)C]WAY-100635-considerations on the validity of cerebellum as a reference region. J Cereb Blood Flow Metab 27:185-195.

Hirvonen J, Karlsson H, Kajander J, Lepola A, Markkula J, Rasi-Hakala H, Nagren K, Salminen JK, Hietala J (2008) Decreased brain serotonin 5-HT1A receptor availability in medication-naive patients with major depressive disorder: an in-vivo imaging study using PET and [carbonyl11C]WAY-100635. Int J Neuropsychopharmacol 11:465-476.

Hornung JP (2010) The neuroanatomy of the serotonergic system. In: Handbook of the behavioral neurobiology of serotonin (Müller CP, Jacobs BL, eds), pp 51-64. London: Academic.

Howell D (2002) Statistical methods for psychology, Ed 5. Belmont, CA: Duxbury.

Ichise M, Liow JS, Lu JQ, Takano A, Model K, Toyama H, Suhara T, Suzuki K, Innis RB, Carson RE (2003) Linearized reference tissue parametric imaging methods: application to [11C]DASB positron emission tomography studies of the serotonin transporter in human brain. J Cereb Blood Flow Metab 23:1096-1112.

Innis RB, Cunningham VJ, Delforge J, Fujita M, Gjedde A, Gunn RN, Holden J, Houle S, Huang SC, Ichise M, et al. (2007) Consensus nomenclature for in vivo imaging of reversibly binding radioligands. J Cereb Blood Flow Metab 27:1533-1539.

Jovanovic H, Cerin A, Karlsson P, Lundberg J, Halldin C, Nordstrom AL (2006) A PET study of 5-HT1A receptors at different phases of the menstrual cycle in women with premenstrual dysphoria. Psychiatry Res 148:185-193.

Jovanovic H, Lundberg J, Karlsson P, Cerin A, Saijo T, Varrone A, Halldin C, Nordstrom AL (2008) Sex differences in the serotonin $1 \mathrm{~A}$ receptor and serotonin transporter binding in the human brain measured by PET. Neuroimage 39:1408-1419.

Kasper S, Stein DJ, Loft H, Nil R (2005) Escitalopram in the treatment of social anxiety disorder: randomised, placebo-controlled, flexible-dosage study. Br J Psychiatry 186:222-226.

Klein N, Sacher J, Geiss-Granadia T, Mossaheb N, Attarbaschi T, Lanzenberger R, Spindelegger C, Holik A, Asenbaum S, Dudczak R, Tauscher J, Kasper S (2007) Higher serotonin transporter occupancy after multiple dose administration of escitalopram compared to citalopram: an [123I]ADAM SPECT study. Psychopharmacology 191:333-339. 
Lammertsma AA, Hume SP (1996) Simplified reference tissue model for PET receptor studies. Neuroimage 4:153-158.

Lanzenberger RR, Mitterhauser M, Spindelegger C, Wadsak W, Klein N, Mien LK, Holik A, Attarbaschi T, Mossaheb N, Sacher J, Geiss-Granadia T, Kletter K, Kasper S, Tauscher J (2007) Reduced serotonin-1A receptor binding in social anxiety disorder. Biol Psychiatry 61:1081-1089.

Le Poul E, Boni C, Hanoun N, Laporte AM, Laaris N, Chauveau J, Hamon M, Lanfumey L (2000) Differential adaptation of brain 5-HT1A and 5-HT1B receptors and 5-HT transporter in rats treated chronically with fluoxetine. Neuropharmacology 39:110-122.

Lowry CA, Johnson PL, Hay-Schmidt A, Mikkelsen J, Shekhar A (2005) Modulation of anxiety circuits by serotonergic systems. Stress 8:233-246.

Mengod G, Cortés R, Vilaró MT, Hoyer D (2010) Distribution of 5-HT receptors in the central nervous system. In: Handbook of the behavioral neurobiology of serotonin (Müller CP, Jacobs BL, eds), pp 123-138. London: Academic.

Meyer JH, Kapur S, Eisfeld B, Brown GM, Houle S, DaSilva J, Wilson AA, Rafi-Tari S, Mayberg HS, Kennedy SH (2001) The effect of paroxetine on 5-HT(2A) receptors in depression: an [(18)F] setoperone PET imaging study. Am J Psychiatry 158:78-85.

Michelsen KA, Prickaerts J, Steinbusch HW (2008) The dorsal raphe nucleus and serotonin: implications for neuroplasticity linked to major depression and Alzheimer's disease. Prog Brain Res 172:233-264.

Monk CS, Telzer EH, Mogg K, Bradley BP, Mai X, Louro HM, Chen G, McClure-Tone EB, Ernst M, Pine DS (2008) Amygdala and ventrolateral prefrontal cortex activation to masked angry faces in children and adolescents with generalized anxiety disorder. Arch Gen Psychiatry 65:568-576.

Moulin-Sallanon M, Charnay Y, Ginovart N, Perret P, Lanfumey L, Hamon M, Hen R, Fagret D, Ibanez V, Millet P (2009) Acute and chronic effects of citalopram on 5-HT1A receptor-labeling by [18F]MPPF and -coupling to receptors-G proteins. Synapse 63:106-116.

Nash JR, Sargent PA, Rabiner EA, Hood SD, Argyropoulos SV, Potokar JP, Grasby PM, Nutt DJ (2008) Serotonin 5-HT1A receptor binding in people with panic disorder: positron emission tomography study. Br J Psychiatry 193:229-234.

Ögren SO, Eriksson TM, Elvander-Tottie E, D'Addario C, Ekström JC, Svenningsson P, Meister B, Kehr J, Stiedl O (2008) The role of 5-HT1A receptors in learning and memory. Behav Brain Res 195:54-77.

Parsey RV, Arango V, Olvet DM, Oquendo MA, Van Heertum RL, John Mann J (2005) Regional heterogeneity of 5-HT1A receptors in human cerebellum as assessed by positron emission tomography. J Cereb Blood Flow Metab 25:785-793.

Parsons LH, Kerr TM, Tecott LH (2001) 5-HT(1A) receptor mutant mice exhibit enhanced tonic, stress-induced and fluoxetine-induced serotonergic neurotransmission. J Neurochem 77:607-617.

Rabiner EA, Messa C, Sargent PA, Husted-Kjaer K, Montgomery A, Lawrence AD, Bench CJ, Gunn RN, Cowen P, Grasby PM (2002) A database of [(11)C]WAY100635 binding to 5-HT(1A) receptors in normal male volunteers: normative data and relationship to methodological, demographic, physiological, and behavioral variables. Neuroimage 15:620-632.

Richardson-Jones JW, Craige CP, Guiard BP, Stephen A, Metzger KL, Kung HF, Gardier AM, Dranovsky A, David DJ, Beck SG, Hen R, Leonardo ED (2010) 5-HT1A autoreceptor levels determine vulnerability to stress and response to antidepressants. Neuron 65:40-52.
Sanchez C, Bergqvist PB, Brennum LT, Gupta S, Hogg S, Larsen A, Wiborg O (2003) Escitalopram, the S-(+)-enantiomer of citalopram, is a selective serotonin reuptake inhibitor with potent effects in animal models predictive of antidepressant and anxiolytic activities. Psychopharmacology (Berl) 167:353-362.

Sharp T, Boothman L, Raley J, Queree P (2007) Important messages in the "post": recent discoveries in 5-HT neurone feedback control. Trends Pharmacol Sci 28:629-636.

Sheline YI, Barch DM, Donnelly JM, Ollinger JM, Snyder AZ, Mintun MA (2001) Increased amygdala response to masked emotional faces in depressed subjects resolves with antidepressant treatment: an fMRI study. Biol Psychiatry 50:651-658.

Sogaard B, Mengel H, Rao N, Larsen F (2005) The pharmacokinetics of escitalopram after oral and intravenous administration of single and multiple doses to healthy subjects. J Clin Pharmacol 45:1400-1406.

Spindelegger C, Lanzenberger R, Wadsak W, Mien LK, Stein P, Mitterhauser M, Moser U, Holik A, Pezawas L, Kletter K, Kasper S (2008) Influence of escitalopram treatment on 5-HT(1A) receptor binding in limbic regions in patients with anxiety disorders. Mol Psychiatry 14:1040-1050.

Sprouse J, Braselton J, Reynolds L, Clarke T, Rollema H (2001) Activation of postsynaptic 5-HT(1A) receptors by fluoxetine despite the loss of firingdependent serotonergic input: electrophysiological and neurochemical studies. Synapse 41:49-57.

Steiger JH (1980) Tests for comparing elements of a correlation matrix. Psychol Bull 87:245-251.

Stein P, Savli M, Wadsak W, Mitterhauser M, Fink M, Spindelegger C, Mien LK, Moser U, Dudczak R, Kletter K, Kasper S, Lanzenberger R (2008) The serotonin-1A receptor distribution in healthy men and women measured by PET and [carbonyl-11C]WAY-100635. Eur J Nucl Med Mol Imaging 35:2159-2168.

Sullivan GM, Ogden RT, Oquendo MA, Kumar JS, Simpson N, Huang YY, Mann JJ, Parsey RV (2009) Positron emission tomography quantification of serotonin-1A receptor binding in medication-free bipolar depression. Biol Psychiatry 66:223-230.

Tork I (1990) Anatomy of the serotonergic system. Ann N Y Acad Sci 600: 9-34, discussion 34-35.

Tzourio-Mazoyer N, Landeau B, Papathanassiou D, Crivello F, Etard O, Delcroix N, Mazoyer B, Joliot M (2002) Automated anatomical labeling of activations in SPM using a macroscopic anatomical parcellation of the MNI MRI single-subject brain. Neuroimage 15:273-289.

Varnas K, Halldin C, Hall H (2004) Autoradiographic distribution of serotonin transporters and receptor subtypes in human brain. Hum Brain Mapp 22:246-260.

Wadsak W, Mien LK, Ettlinger DE, Lanzenberger R, Haeusler D, Dudczak R, Kletter K, Mitterhauser M (2007) Simple and fully automated preparation of [carbonyl-11C]WAY-100635. Radiochim Acta 95:417-422.

Witte AV, Floel A, Stein P, Savli M, Mien LK, Wadsak W, Spindelegger C, Moser U, Fink M, Hahn A, Mitterhauser M, Kletter K, Kasper S, Lanzenberger R (2009) Aggression is related to frontal serotonin-1A receptor distribution as revealed by PET in healthy subjects. Hum Brain Mapp 30:2558-2570.

Wu X, Castren E (2009) Co-treatment with diazepam prevents the effects of fluoxetine on the proliferation and survival of hippocampal dentate granule cells. Biol Psychiatry 66:5-8. 